\title{
Die rol van persoonlikheidsfaktore by die aankoop van 'n motorvoertuig
}

\author{
P.L.S. Ackermann* en P.J. du Plessis \\ Skool vir Bedryfsleiding, Universiteit van Suid-Afrika, Posbus 392, Pretoria, 0001 Republiek van Suid-Afrika
}

Ontvang 9 Junie 1987

\begin{abstract}
The objective of this study was to determine whether there is a relationship between the personality dimensions of consumers and the relative importance that they attach to evaluation criteria when buying a motor vehicle. The sample consisted of 181 white consumers mainly from metropolitan areas. The measuring instruments used in this study were a questionnaire relating to buyers of new and used cars, and the South African Personality Questionnaire. To establish the relationship between the relative importance consumers attach to evaluation criteria and their personality traits, Pearson's product moment correlation coefficient technique was used. Only 21 of the 325 correlations were significant at the 0,01 level.
\end{abstract}

Die doel van hierdie studie was om te bepaal of daar 'n verband bestaan tussen die persoonlikheidstrekke van verbruikers en die relatiewe belangrikheid van evalueringskriteria by motorvoertuigaankope. Die steekproef het bestaan uit 181 blanke verbruikers van hoofsaaklik metropolitaanse gebiede. Die meetinstrumente wat in hierdie studie gebruik is, is ' $n$ vraelys wat op kopers van nuwe of gebruikte motors betrekking het, en die SuidAfrikaanse Persoonlikheidsvraelys. Om die verband tussen die relatiewe belangrikheid wat verbruikers aan evalueringskriteria heg en hulle persoonlikheidstrekke te bepaal, is van Pearson se produk-momentkorrelasiekoëffisiënt-tegniek gebruik gemaak. Slegs 21 van die 325 korrelasies was beduidend op die 0,01-vlak.

* Aan wie korrespondensie gerig moet word

Die doelwit van navorsing oor persoonlikheid in die verbruikersveld is hoofsaaklik om marksegmente aan die hand van persoonlikheidseienskappe te identifiseer. 'n Grondliggende opvatting by hierdie segmentasie van verbruikers op grond van persoonlikheid, is dat 'n verbruiker se aankoopgedrag ten dele 'n weerspieëling van sy persoonlikheid is. Navorsing oor die verband tussen persoonlikheid en aankoopgedrag het nog nie ondubbelsinnige en oortuigende resultate opgelewer nie (Schiffman \& Kanuk, 1983). Netso het Kassarjian \& Sheffet (1975) tot die slotsom gekom dat, volgens navorsingsresultate, persoonlikheidsveranderlikes slegs 'n geringe proporsie variansie van verbruikersgedrag verklaar. Verskeie navorsers soos Akaah \& Riordan (1982), Alpert (1972), Birdwell (1968), Evans (1959; 1968), Green, Maheshwari \& Rao (1969), Grubb \& Hupp (1968), Jacoby (1969), O’Brien, Tapia \& Brown (1977), Sirgy (1980, 1982a, 1982b), Sparks \& Tucker (1971) en Westfall (1962) het persoonlikheidsfaktore in verband probeer bring met byvoorbeeld motorhandelsmerk, advertensiestrategie en motorontwerp. Westfall (1962), Kuehn (1963) en Grubb \& Hupp (1968), het wel statisties beduidende verbande tussen persoonlikheid van die verbruiker (motorkoper) en sy aankoopgedrag gevind. Kassarjian (1971) het egter tot die slotsom gekom dat die resultate van studies oor persoonlikheid en verbruikersgedrag twyfelagtig was. Ander navorsers soos Evans $(1959 ; 1968)$ het tot die gevolgtrekking gekom dat persoonlikheid 'n onbevredigende voorspellingsveranderlike van verbruikersgedrag skyn te wees. Engel, Blackwell \& Miniard (1986: 252) verklaar dat daar nog nie afdoende bewys gelewer is dat persoonlikheid ' $n$ bruikbare wyse is om markte te segmenteer nie.

Alpert (1972: 89-92) kon nie 'n betekenisvolle verband tussen persoonlikheid en handelsmerk vind nie, maar eerder tussen die verbruiker se persoonlikheid en die relatiewe belangrikheid wat 'n koper op verskeie produkattribute (evalueringskriteria) plaas. Die verkenningsontwerp en die steekproef (slegs studente) het die bevindinge van daardie navorsing egter beperk in die opsig dat dit nie na ander verbruikersgroepe en produkte veralgemeen kan word nie.

Ackermann (1976), wat sy studie ter plaatse gedoen het, kon geen beduidende verskille tussen die persoonlikheidstrekke van kliënte wat verskillende tipes finansiële instellings vir spaardoeleindes ondersteun, vind nie. Hoewel sy studie oor spaargedrag van bank-en bougenootskappe gehandel het, suggereer dit tog dat soortgelyke bevindige ook moontlik in die onderhawige studie gevind mag word.

In Suid-Afrika is persoonlikheidseienskappe en die verband daarvan met kriteria wat by die aankoop van 'n motorvoertuig deur 'n verbruiker oorweeg word egter nog nie in navorsing ondersoek nie.

Die doel van hierdie studie was om vas te stel of daar 'n verband bestaan tussen die persoonlikheidseienskappe van 'n verbruiker en die relatiewe belangrikheid wat by die aankoop van ' $n$ motorvoertuig aan evalueringskriteria geheg word. Meer spesifiek is die hipotese ondersoek dat daar geen verband bestaan tussen die relatiewe belangrikheid wat verbruikers aan evalueringskriteria heg en hulle persoonlikheidseienskappe nie. Die bevindings sal daartoe bydra om die relatief $\min$ Suid-Afrikaanse navorsing wat in die afgelope jare oor die verband tussen persoonlikheid en verbruikersgedrag gedoen is, aan te vul.

\section{Metode}

Proefpersone

Die steekproef het bestaan uit 181 blanke persone, hoofsaaklik uit metropolitaanse gebiede, wat tussen 
Desember 1985 en Mei 1986 'n nuwe of gebruikte motor vir privaatgebruik gekoop het. Die demografiese besonderhede van die respondente word in Tabel 1 aangetoon.

\section{Meetinstrumente}

Die meetinstrumente wat in hierdie studie gebruik is, is in die vorm van twee vraelyste. Die eerste vraelys het betrekking op kopers van nuwe of gebruikte motors,

Tabel 1 Demografiese eienskappe van respondente wat die Suid-Afrikaanse persoonlikheidsvraelys voltooi het

\begin{tabular}{|c|c|c|}
\hline Klassifikasie & Aantal & $\%$ van totaal \\
\hline \multicolumn{3}{|l|}{ 1. Geslag } \\
\hline Manlik & 155 & 85,6 \\
\hline Vroulik & 26 & 14,4 \\
\hline \multicolumn{3}{|l|}{ 2. Huistaal } \\
\hline Afrikaans & 86 & 47,5 \\
\hline Engels & 95 & 52,5 \\
\hline \multicolumn{3}{|l|}{ 3. Onderwyspeil } \\
\hline St. 8 & 6 & 3,3 \\
\hline Matriek & 34 & 18,8 \\
\hline Naskoolse diploma & 60 & 33,1 \\
\hline Universiteitsgraad & 81 & 44,8 \\
\hline \multicolumn{3}{|l|}{ 4. Beroepsgroep } \\
\hline Polisie/Weermag & 1 & 0,6 \\
\hline Klerklik/Verkope & 27 & 14,7 \\
\hline Professioneel & 61 & 33,7 \\
\hline Vakman/geskoolde werker & 13 & 7,2 \\
\hline Eie besigheid & 6 & 3,3 \\
\hline Huisvrou/tuisteskepper & 1 & 0,6 \\
\hline Student & 1 & 0,6 \\
\hline Bestuur/Uitvoerend & 67 & 37,0 \\
\hline Fabriekswerker & 1 & 0,6 \\
\hline Afgetree & 3 & 1,7 \\
\hline \multicolumn{3}{|l|}{ 5. Ouderdom (jaar) } \\
\hline $18-24$ & 6 & 3,3 \\
\hline $25-30$ & 30 & 16,6 \\
\hline $31-35$ & 39 & 21,5 \\
\hline $36-45$ & 64 & 35,4 \\
\hline $46-55$ & 32 & 17,7 \\
\hline $56-64$ & 6 & $\mathbf{3 , 3}$ \\
\hline $65+$ & 4 & 2,2 \\
\hline \multicolumn{3}{|l|}{ 6. Huwelikstatus } \\
\hline Huidiglik getroud & 156 & 86,2 \\
\hline Geskei & 9 & 5,0 \\
\hline Nooit getroud & 14 & 7,7 \\
\hline Wedustaat & 2 & 1,1 \\
\hline \multicolumn{3}{|l|}{$\begin{array}{l}\text { 7. Bruto huishoudelike maan- } \\
\text { delikse inkomste }\end{array}$} \\
\hline Minder as R600 & - & - \\
\hline R600-R999 & 2 & 1,1 \\
\hline R1000-R1499 & 6 & 3,3 \\
\hline R1500-R1999 & 19 & 10,5 \\
\hline R2000-R2999 & 48 & 26,5 \\
\hline R3000-R3999 & 62 & 34,3 \\
\hline R4000+ & 44 & 24,3 \\
\hline
\end{tabular}

terwyl die tweede die Suid-Afrikaanse Persoonlikheidsvraelys (SAPV) is. Die 65 evalueringskriteria wat by die eerste vraelys ingesluit is, word in Tabel 2 weergegee.

\section{Beoordeling}

Indien ' $n$ respondent ' $n$ kriterium geensins as belangrik beskou het nie, is daar aan die respons ' $n$ telling van een toegeken, terwyl 'n telling van ses toegeken is indien 'n kriterium as uiters belangrik beskou is. Die SAPV bestaan uit vyf bipolêre skale en meet die volgende persoonlikheidstrekke: sosiale responsiwiteit, angs, vyandigheid, onbuigsaamheid en dominansie. Die vyf persoonlikheidsdimensies wat in die vraelys verteenwoordig word, is gekies vanweë hulle waargenome bruikbaarheid in werk- en navorsingstoepassings (Huysamen 1983).

\section{Ontleding van gegewens}

Om die verband te bepaal tussen die relatiewe belangrikheid wat verbruikers aan evalueringskriteria

Tabel 2 Evalueringskriteria by die aankoop van 'n motorvoertuig vir privaatgebruik

1. Gehalte van vakmanskap

34. Padtoetsverslae

2. Onbeperkte uitsig

35. Kredietreëlings

3. Reputasie van motorvervaardigers 36. Lugtoevoerstelsels

4. Verhouding met verkooppersoneel 37. Aankoopprys van handelaar

5. Bagasieruimte

6. Statusindruk van motor

38. Stilering/voorkoms

7. Stilheid van enjin/transmissie

39. Versnelling

8. Instandhoudingskoste

9. Fatsoen/vorm

10. Gemak van voorsitplekke

11. Enjingrootte

12. Geraasvlak binne motor

13. Betroubaarheid van model

14. Luuksheid binne

15. Lae loopkoste

16. Prestige waarde

17. Mening van kollegas

18. Toekomstige herverkoopwaarde

19. Houding van verkoopperssoneel

20. Binneruimte

21. Werkverrigting van enjin

22. Land van herkoms

23. Reputasie van model

24. Voorkoms van vertoonkamer

25. Beskikbaarheid van onderdele

26. Gemak van agtersitplekke

27. Kontantafslag

28. Instrumentasie van paneelbord

29. Brandstofdoeltreffendheid

30. Enjinkrag

31. Waarborgtydperk

32. Vorige ervaring met handelaar

33. Reputasie van na-verkope diens ondersteuning
40. Veiligheidskenmerke

42. Toetsrit

43. Gerief vir passasiers

44. Hoespoedverrigting

45. Spesiale aanbieding

46. Mening van vriende

47. Invloed van verkooppersoneel

48. Radio-advertensie

49. Rygemak

50. Reikafstand van brandstoftenk

51. Padhouvermoë

52. Reputasie van handelaar

53. TV-advertensie

54. Ruimheid vir bestuurder

55. Agterwielaandrywing

56. Ruimheid vir agterpassasiers

57. Gemak van bestuur

58. Spieëltjie op bestuurder se sonskerm

59. Beenruimte voor

60. Ligging van handelaar

61. Koste van onderdele

62. Mening van familie

63. Tegniese gevorderdheid

64. Voorwiclaandrywing

65. Goeie inruilwaarde vir vorige motor
41. Uitgebreide handelaametwerk 
heg en hulle persoonlikheidsdimensies, is van Pearson se produkmoment-korrelasietegniek gebruik gemaak. Die korrelasies is bereken tussen die waardes aan die 65 evalueringskriteria toegeken en die tellings behaal op elke persoonlikheidsdimensie.

\section{Resultate}

Die korrelasiekoëffisiënte wat tussen elke persoonlikheidsdimensie en die verskillende evalueringskriteria bereken is, word in Tabel 3 aangedui. Dit blyk dat daar ' $n$ beduidende verband op die 0,01-vlak tussen sosiale responsitiwiteit en slegs een evalueringskriterium, naamlik kontantafslag ( $\mathrm{nr} 27$ ) is.

Onbeduidende verbande kom by 64 evalueringskriteria $(98 \%)$ voor. Die nul-hipotese word dus ten opsigte van 'sosiale responsitiwiteit' en slegs een evalueringskriterium verwerp ten gunste van die alternatiewe hipotese. Uit Tabel 3 kan afgelei word dat daar ' $n$ beduidende verband op die 0,01-vlak tussen die persoonlikheidsdimensie angs en drie evalueringskriteria, naamlik statusindruk van motor (nr 6), werkverrigting van enjin ( $\mathrm{nr} 21$ ) en hoëspoedverrigting (nr 44) bestaan.

Onbeduidende verbande kom by 62 evalueringskriteria $(95 \%)$ voor. Die nul-hipotese word ten opsigte van 'angs' en drie evalueringskriteria verwerp ten gunste van die alternatiewe hipotese.

Tabel 3 toon dat daar 'n beduidende verband tussen die persoonlikheidsdimensie vyandigheid en ses evalueringskriteria op die 0,01-vlak is, naamlik bagasieruimte ( $\mathrm{nr} 5$ ), instandhoudingskoste ( $\mathrm{nr} 8$ ), lae loopkoste ( $\mathrm{nr}$ 15), binneruimte ( $\mathrm{nr} 20$ ), gemak van agtersitplekke (nr 26) en brandstofdoeltreffendheid (nr 29).
Onbeduidende verbande kom by 59 evalueringskriteria $(91 \%)$ voor. Die nul-hipotese word ten opsigte van 'vyandigheid' en ses evalueringskriteria verwerp ten gunste van die alternatiewe hipotese.

Uit Tabel 3 blyk dit verder dat daar 'n beduidende verband op die 0,01-vlak tussen die dimensie onbuigsaamheid en vier evalueringskriteria, naamlik kontantafslag ( $\mathrm{nr} 27$ ), aankoopprys (nr 37), reikafstand van brandstoftenk (nr 50) en agterwielaandrywing (nr 55) bestaan.

Onbeduidende verbande kom by 61 evalueringskriteria $(94 \%)$ voor. Die nul-hipotese word ten opsigte van 'onbuigsaamheid' en vier evalueringskriteria verwerp ten gunste van die alternatiewe hipotese. Sewe evalueringskriteria in Tabel 3 toon 'n beduidende verband met die persoonlikheidsdimensie dominansie, naamlik statusindruk van motor ( $\mathrm{nr}$ 6), instandhoudingskoste ( $\mathrm{nr}$ 8), geraasvlak binne motor ( $\mathrm{nr} 12)$, luuksheid binne ( $\mathrm{nr}$ 14), lae loopkoste ( $\mathrm{nr} 15)$, kontantafslag ( $\mathrm{nr}$ 27) en mening van vriende ( $\mathrm{nr}$ 46).

Onbeduidende verbande kom by 58 evalueringskriteria $(89 \%)$ voor. Die nul-hipotese word dus ten opsigte van 'dominansie' en sewe evalueringskriteria verwerp ten gunste van die alternatiewe hipotese.

\section{Bespreking}

In die onderhawige studie is daar 21 beduidende korrelasies op die 0,01-vlak tussen die vyf persoonlikheidsdimensies en 65 evalueringskriteria gevind. Uit die 325 korrelasiekoëffisiënte (vyf persoonlikheidsdimensies $\times 65$ evalueringskriteria) was dus slegs $6,5 \%$ beduidend. Die gemeenskaplike variansie van die twee soorte veranderlikes is dus relatief laag. Byvoorbeeld, die korrelasiekoëffisiënt tussen die persoonlikheidsdimensie onbuigsaamheid en die

Tabel 3 Korrelasiekoëffisiënte tussen sommige persoonlikheidsdimensies van verbruikers en die waarde wat hulle aan evalueringskriteria heg

\begin{tabular}{rlccccc}
\hline & & Sosiale & & & \\
& Evalueringskriterium & responsitiwiteit & Angs & Vyandigheid & Onbuigsaamheid & Dominansie \\
\hline 5 & Bagasieruimte & 0,068 & 0,001 & $-0,237^{*}$ & 0,112 & $-0,026$ \\
6 & Statusindruk van motor & 0,109 & $-0,183^{*}$ & 0,018 & 0,088 & $0,204^{*}$ \\
8 & Instandhoudingskoste & 0,045 & 0,067 & $-0,191^{*}$ & $-0,082$ & $-0,188^{*}$ \\
12 & Geraasvlak binne motor & 0,077 & $-0,093$ & $-0,034$ & 0,066 & $0,171^{*}$ \\
14 & Luuksheid binne & 0,090 & $-0,018$ & 0,042 & 0,129 & $0,230^{*}$ \\
15 & Lae loopkoste & $-0,013$ & 0,036 & $-0,174^{*}$ & $-0,010$ & $-0,188^{*}$ \\
20 & Binneruimte & $-0,017$ & 0,057 & $-0,181^{*}$ & 0,090 & $-0,023$ \\
21 & Werkverrigting van enjin & 0,019 & $-0,165^{*}$ & $-0,108$ & $-0,005$ & $-0,023$ \\
26 & Gemak van agtersitplekke & $-0,022$ & $-0,074$ & $-0,201^{*}$ & 0,080 & $-0,028$ \\
27 & Kontantafslag & $0,165^{*}$ & $-0,159$ & 0,055 & $-0,184^{*}$ & $0,202^{*}$ \\
29 & Brandstofdoeltreffendheid & 0,024 & $-0,030$ & $-0,208^{*}$ & $-0,066$ & $-0,096$ \\
37 & Aankoopprys & $-0,006$ & 0,092 & $-0,003$ & $-0,255^{*}$ & $-0,063$ \\
44 & Hoëspoedverrigting & 0,054 & $-0,200^{*}$ & 0,145 & $-0,007$ & 0,034 \\
46 & Mening van vriende & $-0,009$ & $-0,009$ & 0,061 & $-0,042$ & $0,206^{*}$ \\
50 & Reikafstand van brandstoftenk & $-0,006$ & $-0,006$ & $-0,038$ & $0,165^{*}$ & 0,004 \\
55 & Agterwielaandrywing & 0,001 & $-0,048$ & $-0,149$ & $0,196^{*}$ & $-0,024$ \\
\hline
\end{tabular}

- $P<0,01$ 
evalueringskriterium aankoopprys is $-0,255$ (sien Tabel $3)$. Hierdie is die hoogste korrelasie wat verkry is en verteenwoordig slegs $6,2 \%$ gemeenskaplike variansie. Oorsaaklike verbande tussen die waarde wat aan evalueringskriteria toegeken is en die verskillende persoonlikheidsdimensies, is nie bepaal nie. Daar word dus gesuggereer dat die resultate van hierdie studie, met betrekking tot die verbande wat vasgestel is, versigtig vertolk en gebruik moet word, veral as voorspellers van verbruikersgedrag. Die bevindinge kan as rigtingwysers dien om, in samehang met ander tegnieke soos psigografiese segmentasie, verbruikersgedrag te probeer verklaar.

Moontlike tekortkominge in hierdie studie is dat die studie slegs op blankes uitgevoer is, omdat die meetinstrument slegs vir blankes gestandaardiseer is. 'n Sterk element van sydigheid kan bespeur word in die steekproefsamestelling aangesien $58 \%$ van die respondente in die hoër inkomstegroep val en $70 \%$ van die respondente in die professionele en bestuur/ uitvoerende beroepsgroep resorteer. In hierdie studie is die rol wat persoonlike omstandighede soos byvoorbeeld geslag, ouderdom, inkomste en aantal afhanklikes, as moderators in die beoordeling van evalueringskriteria kan speel, nie in berekening gebring nie. Die resultate van hierdie studie is in ooreenstemming met vorige navorsing oor die verband tussen verbruikersgedrag en persoonlikheidstrekke, waar onoortuigende resultate verkry is.

Die bevinding dat relatief min beduidende verbande tussen persoonlikheidseienskappe en evalueringskriteria bestaan, en die feit dat die beduidende verbande wat wel bestaan, min gemeenskaplike variansie verklaar, suggereer dat die gebruik van persoonlikheidseienskappe as 'n onafhanklike segmentasieveranderlike, per se, nie lukraak gebruik moet word in bemarkingstrategie-formulering nie.

Verdere navorsing met 'n meer heterogene steekproef mag interessante resultate oplewer, byvoorbeeld met betrekking tot ouderdomsgroepverskille by persoonlikheidseienskappe en motorevalueringskriteria.

\section{Summary}

The objective of research regarding personality in the consumer field is primarily to identify marketing segments by means of personality traits. A general view with respect to this kind of segmentation is that a consumer's buying behaviour is partly a reflection of his personality. The objective of this study was to determine whether there is a relationship between the personality dimensions of consumers and the relative importance that they attach to evaluation criteria when buying a motor vehicle. The sample consisted of 181 white consumers, mainly from metropolitan areas. The measuring instruments used in this study were a questionnaire relating to buyers of new and used cars, and the South African Personality Questionnaire. The first questionnaire includes 65 evaluation criteria that a consumer could consider when buying a car. The response to each criterion was assessed on a six-point scale. The South African Personality Questionnaire is a standardized test and consists of five bipolar scales measuring social responsiveness, anxiety, hostility, inflexibility and dominance. To establish the relationship between the relative importance consumers attach to evaluation criteria and their personality traits the Pearson product moment correlation coefficient technique was used. Of the 325 correlations only 21 were significant at the 0,01 level of significance. The results of this study are in accordance with previous research on the relationship between consumer's behaviour and their personality traits, which led to ambiguous and unconvincing results. The findings suggest that marketers must be extremely cautious when they try to use personality traits to assist them in strategic marketing planning.

\section{Verwysings}

Ackermann, P.L.S. 1976. Spaargedrag van bank- en bougenootskapkliënte. Ongepubliseerde Ph.D-proefskrif. Pretoria; Universiteit van Suid-Afrika.

Akaah, I.P. \& Riordan, E.A. 1982. Self-brand image and the effects of trait desirability. In:An assessment of marketing thought and practice. Educator's Conference Proceedings.

Walker, B.J., et al. (Ed.) Series no. 48. Chicago: Americam Marketing Association.

Alpert, M.I. 1972. Personality and the determinants of product choice. J. Mark. Res., vol. 9, 89-92.

Birdwell, A.C. 1968. A study of the influence of image congruence on consumer choice. J. Bus., vol. 41, 76-88.

Engel, J.F., Blackwell, R.D. \& Miniard, P.W. 1986. Consumer behaviour. Sth Edition. Illinois: Dryden Press.

Evans, F.B. 1959. Psychological and objective factors in the prediction of brand choice. Ford versus Chevrolet $J$ Bus., vol. 31, 340-369.

Evans, F.B. 1968. Ford versus Chevrolet: Park Forest revisited. J. Bus., vol. 32, 445-459.

Green, P.E., Maheshwari, R. \& Rao, V.R. 1969. Self concept and brand preference: an empirical application of multi-dimensional scaling. J Market Res. Soc., vol. 2, 343-360.

Grubb, E.L. \& Hupp, G. 1968. Perception of self-generalized stereotypes and brand selection. $J$ Market. Res., vol. 5, $58-63$.

Huysamen, G.K. 1983. Psychological Measurement. Pretoria: Academica.

Jacoby,J. 1969. Personality and consumer behaviuor: how not to find relationships. Aangehaal in Schiffman, L.G. \& Kanuk, L.L. 1983. Consumer behaviour. 2de Uitgawe. Englewood Cliffs, New Jersey: Prentice-Hall, Inc.

Kassarjian, H.H. 1971. Personality and consumer behaviour: a review. J. Market. Res., vol. 8, 409-418.

Kassarjian, H.H. \& Sheffet, M.J. 1975. Personality and consumer behaviour: One more time. Readings in consumer behaviour, Wallendorf,M. \& Zaltman, G. (Eds.) 1984. New York: John Wiley \& Sons.

Kuehn, A.A. 1963. Demonstration of a relationship between psychological factors and brand choice. J. Bus., vol. 36, 237-241. 
O'Brien, T.V., Tapia, H.S. \& Brown, T.L. 1977. The self-concept in buyer behaviour. Bus. Hor., October, 65-71.

Schiffman, L.G. \& Kanuk, L.L. 1983. Consumer behaviour. 2nd Edition. New Jersey: Prentice-Hall Inc.

Sirgy, M.J. 1980. The self-concept in relation to product preference and purchase intention. In: Developments in marketing science., vol. 3, Bellur, V.V. Ed. Marquette, Mi: Academy of Marketing Science, 350-354.
Sirgy, M.J. 1982a. Self-image/product image conqruity and advertising strategy . In: Developments in marketing science, vol. 5, Kothari, V. Ed. Marquette, Mi: Academy of Marketing Science, 129-133.

Sirgy, M.J. 1982b. Self-concept in consumer behaviour: A critical review. J. Cons. Res., vol. 9, 287-300.

Sparks, D.I. \& Tucker, W.T. 1971. A multivariate analysis of personality and product use. J. Market. Res., vol. 8, 67-70.

Westfall, R. 1962. Psychological factors in predicting product choice. J.Market., vol. 26, 34-40. 